\title{
In Vitro Effect of Putty Calcium Silicate Materials on Human Periodontal Ligament Stem Cells
}

\author{
Francisco Javier Rodríguez-Lozano ${ }^{1,2, *(\mathbb{D})}$, Sergio López-García $\left.{ }^{3}{ }^{(}\right)$, David García-Bernal ${ }^{1}(\mathbb{D}$, \\ Miguel R. Pecci-Lloret ${ }^{2}$, Julia Guerrero-Gironés ${ }^{2}$, María P. Pecci-Lloret ${ }^{2}$, Adrián Lozano ${ }^{4}$, \\ Carmen Llena ${ }^{4}\left(\mathbb{D}\right.$, Gianrico Spagnuolo ${ }^{5,6}\left(\mathbb{D}\right.$ and Leopoldo Forner ${ }^{4}(\mathbb{D})$
}

1 Research Group Cellular Therapy and Hematopoietic Transplant, Biomedical Research Institute, Virgen de la Arrixaca Clinical University Hospital, IMIB-Arrixaca, University of Murcia, 30120 Murcia, Spain; redond@gmail.com

2 Clínica Odontológica Universitaria, Morales Meseguer Hospital, Faculty of Medicine, University of Murcia, 30007 Murcia, Spain; miguelr.pecci@gmail.com (M.R.P.-L.); juliaguerrero1@hotmail.com (J.G.-G.); mpilar.pecci@gmail.com (M.P.P.-L.)

3 Department of Genetics, Faculty of Biology, University of Murcia, 30100 Murcia, Spain; slg4850@gmail.com

4 School of Dentistry, Faculty of Medicine, University of Valencia, 46010 Valencia, Spain; adrianlozano@mac.com (A.L.); llena@uv.es (C.L.); forner@uv.es (L.F.)

5 Department of Neurosciences, Reproductive and Odontostomatological Sciences, University of Naples "Federico II", 80138 Napoli, Italy; gspagnuo@unina.it

6 Institute of Dentistry, I. M. Sechenov First Moscow State Medical University, 119146 Moscow, Russia

* Correspondence: fcojavier@um.es; Tel.: +34-868889518

Received: 24 November 2019; Accepted: 23 December 2019; Published: 1 January 2020

\begin{abstract}
New bioactive materials have been developed for retrograde root filling. These materials come into contact with vital tissues and facilitate biomineralization and apical repair. The objective of this study was to evaluate the cytocompatibility and bioactivity of two bioactive cements, Bio-C Repair (Angelus, Londrina, Pr, Brazil) and TotalFill BC RRM putty (FGK, Dentaire SA, La-Chaux-de-fonds, Switzerland). The biological properties in human periodontal ligament stem cells (hPDLSCs) that were exposed to Bio-C Repair and TotalFill BC RRM putty were studied. Cell viability, migration, and cell adhesion were analyzed. Moreover, qPCR and mineralization assay were performed to evaluate the bioactivity potential of these cements. The results were statistically analyzed using ANOVA and the Tukey test $(p<0.05)$. It was observed that cell viability and cell migration in Bio-C Repair and TotalFill BC RRM putty were similar to the control without statistically significant differences, except at $72 \mathrm{~h}$ when TotalFill BC RRM putty was slightly lower $(p<0.05)$. Excellent cell adhesion and morphology were observed with both Bio-C Repair and TotalFill BC RRM putty. Both cements promoted the osteo- and cementogenic differentiation of hPDLSCs. These results suggest that Bio-C Repair and TotalFill BC RRM putty are biologically appropriate materials to be used as retrograde obturation material.
\end{abstract}

Keywords: retrograde filling materials; biocompatibility; apical surgery; periodontal ligament stem cells; endodontic

\section{Introduction}

In our daily practice, it is common to find in some problematic cases with lesions such as external or internal resorption, iatrogenic perforations, or periapical lesions that have a doubtful prognosis especially when there is a radiolucent area adjacent to the perforation site, and therefore it is necessary to perform apical surgery with a retrograde root filling [1,2]. 
Periapical surgery is the last option to save a tooth before performing the extraction when a periapiapical lesion cannot be managed with conventional endodontic retreatment. To achieve the treatment, the material is placed in the root-end cavity sealing the entire area [3-5]. This area is where the stem cells from the periodontal ligament (PDLSCs) are located and are in direct contact with the retrograde root filling material $[6,7]$. The interaction between the PDLSCs and the material should improve the regeneration of the area; several studies have proven that it favors the healing of the cementum, alveolar bone, gingiva, and periodontal ligament $[8,9]$. Therefore, it is crucial to conduct cytocompatibility studies of these calcium silicate-based materials and because it is a complicated and challenging treatment, we need the properties of the materials to be optimal [10].

Over the years, the most commonly used materials to perform a retrograde root filling have been mineral trioxide aggregate (MTA), Biodentine, amalgam, super ethoxy benzoic acid (super EBA). However, new materials are appearing on the market, such as calcium silicate materials [2].

Calcium silicate-based materials with numerous properties are appearing on the market that makes them ideal for these cases [11]. Calcium silicate materials are cements with a formulation based on MTA-like material or with minor modifications. Different cements have been studied in the last years and have demonstrated their numerous advantages [12,13]. So far, there is no specific material that meets all the necessary properties (antimicrobial, physical, chemical, and ease of handling) for these situations [14-16]. It is important to note that one material with all these requirements would cause an improvement in the prognosis of these treatments.

Bio-C Repair (Angelus, Londrina, Pr, Brazil) (BCR) is available in an individual syringe and TotalFill BC RRM putty (FGK, Dentaire SA, La-Chaux-de-fonds, Switzerland) (TFB) is available in a jar; both have an excellent consistency to facilitate handling unlike MTA or amalgam, and according to the manufacturer, are bioactive, antibacterial, nonstaining, and promote healing. Some tests were used to check whether these substances are cytotoxic [17].

This study aims to compare the cytotoxic effects and the bioactivity potential of two premixed materials used in retrograde root filling surgery such as BCR and TFB with PDLSCs.

\section{Material and Methods}

\subsection{Isolation of Human Periodontal Ligament Stem Cells (hPDLSCs)}

The Ethical Committee of the University of Murcia approved the present study (ID: 2199/2018). Wisdom molars $(n=10)$ were extracted and transported to the laboratory in Minimum Essential Medium Alpha ( $\alpha$-MEM) (Gibco, Invitrogen, Carlsbad, CA, USA) solution containing $1 \%$ antibiotics (Sigma-Aldrich, St. Louis, MO, USA) and fungi zone maintained at $4{ }^{\circ} \mathrm{C}$. Next, after washing three times with PBS, the periodontal tissues were scraped from the middle and the apical part of the root surface and were cut into small fragments with surgical blades. The fragment tissues were digested with an enzymatic solution, Collagenase type I (Gibco, Gaithersburg, MD, USA) during $1 \mathrm{~h}$ at $37^{\circ} \mathrm{C}$. Then, periodontal cells were seeded in Minimum Essential Medium Alpha with $10 \%$ fetal bovine serum (Sigma-Aldrich, St. Louis, MO, USA) and 1\% penicillin/streptomycin (Sigma-Aldrich, St. Louis, $\mathrm{MO}, \mathrm{USA}$ ). Culture medium was replaced every three days. Cells at passages 2 to 4 were used for subsequent experiments.

\subsection{Flow Cytometric Characterization}

The expression of cell surface markers was detected using fluorescence-activated cell sorting (FACS) (Calibur Flow Cytometer, BD Biosciences, San José, CA, USA). Flow cytometry was used to analyze the immunophenotype of cells at passage 3 . Briefly, hPDLSCs $\left(2 \times 10^{5}\right)$ were trypsinized, washed with PBS, and then incubated for $15 \mathrm{~min}$ at $4{ }^{\circ} \mathrm{C}$ with monoclonal antibodies conjugated with fluorescent dyes. The following antibody cocktails were used: MSC-positive cocktail (CD90, CD105, and CD73) and MSC-negative cocktail (CD34, CD14, CD20, and CD45) (MiltenyiBiotec, Bergisch Gladbach, Germany). Results were evaluated using FlowJo software (FlowJo LLC, Ashland, OR, USA). 


\subsection{Sample Extracts}

BCR and TFB were tested (Table 1). Under aseptic conditions, discs of these cements (diameter $5 \mathrm{~mm}$ and height $2 \mathrm{~mm}$ ) were prepared and stored in Minimum Essential Medium Alpha to achieve setting. Following the recommendations of ISO 10993-5 (Biological evaluation of medical devices-Part 5: Tests for in vitro cytotoxicity) and ISO 10993-12 (Part 12: Sample preparation and reference materials), cements extracts were collected and diluted in free-serum culture medium $(1: 1,1: 2$, and 1:4) [18].

Table 1. Materials tested.

\begin{tabular}{|c|c|c|}
\hline Materials & Manufacturer & Composition \\
\hline BIO-C Repair & $\begin{array}{c}\text { Angelus, } \\
\text { Londrina, Brasil. }\end{array}$ & $\begin{array}{c}\text { Powder: Calcium Silicate }\left(\mathrm{Ca}_{2} \mathrm{SiO}_{4}\right) \text {, Calcium Oxide }(\mathrm{CaO}) \text {, } \\
\text { Zirconium Oxide }\left(\mathrm{ZrO}_{2}\right) \text {, Iron Oxide }\left(\mathrm{Fe}_{2} \mathrm{O}_{3}\right) \text {, Silicon } \\
\text { Dioxide }\left(\mathrm{SiO}_{2}\right) \text { and Dispersing Agent }\end{array}$ \\
\hline $\begin{array}{c}\text { TOTALFILL } \\
\text { BC RRM Putty }\end{array}$ & $\begin{array}{l}\text { Innovative BioCeramix Inc. } \\
\text { Burnaby, } \\
\text { Canada }\end{array}$ & $\begin{array}{l}\text { Powder: Tricalcium Silicate }\left(\mathrm{Ca}_{3} \mathrm{SIO}_{4}\right) \text {, Dicalcium Silicate } \\
\left(\mathrm{Ca}_{2} \mathrm{SiO}_{4}\right) \text {, Zirconium Oxide }\left(\mathrm{ZrO}_{2}\right) \text {, Tantalum Pentoxide } \\
\left(\mathrm{Ta}_{2} \mathrm{O}_{5}\right) \text {, Calcium Sulfate }\left(\mathrm{CaSO}_{4}\right) .\end{array}$ \\
\hline
\end{tabular}

\subsection{Cytotoxicity Evaluation}

The methyl thiazolyltetrazolium (MTT) (3-(4, 5-dimethylthiazol- 2-yl) -2, 5-diphenyltetrazolium bromide) assay (Sigma) was conducted to detect the metabolic activity, as described previously [19]. Briefly, hPDLSCs were cultured in 96-well plates (2000 cell/well) and treated differentially according to the experimental design (1:1, 1:2, and 1:4 extracts) for $72 \mathrm{~h}$. Cells without extracts served as control. In accordance with the manufacturer's instructions (Sigma) the MTT reagent was added to the wells for $4 \mathrm{~h}$. When the purple precipitate was obviously noticeable, dimethyl sulfoxide (DMSO) (100 $\mu \mathrm{L} /$ well) was added to create the formazan dye soluble. The cover was removed, and the light absorption in each well was evaluated by spectrophotometer (Synergy H1, BioTek, Winooski, VT, USA) at $570 \mathrm{~nm}$ (Abs 570).

\subsection{Scratch Migration Assay}

To assess the effect of different cement extracts on hPDLSCs migration, scratch migration assay was performed. $2 \times 10^{5} \mathrm{hPDLSC} /$ well were seeded onto six-well plates $(\mathrm{n}=3)$ and proliferated to achieve confluency. A scratch was made with a $200 \mu \mathrm{L}$ pipette tip, and each well was washed three times to remove cell debris using PBS. The wound closure was evaluated at $24 \mathrm{~h}, 48 \mathrm{~h}$, and $72 \mathrm{~h}$. The wound closure was evaluated using photographs and ImageJ software (National Institutes of Health, Bethesda, MD, USA) to quantify the wound area at three time points after the scratch. The width of the scratches was measured during the following three periods: 0 to $24 \mathrm{~h}$ (first period), 24 to $48 \mathrm{~h}$ (second period), and 48 to $72 \mathrm{~h}$ (third period). Cells without extracts served as control.

\subsection{Scanning Electronic Microscopy}

For the scanning electron microscope (SEM) analysis, root repair cements were mixed and transferred to previously prepared molds that were $2 \mathrm{~mm}$ thick and $5 \mathrm{~mm}$ in diameter. Then, discs were subdivided into two groups $(\mathrm{n}=3)$. After three days of cell culture on the discs, cells were fixed with $4 \%$ glutaraldehyde in PBS for four hours and dehydrated, air-dried, and sputter-coated with palladium-gold. Finally, cell morphology was evaluated using $100 \times$ and $300 \times$ magnifications. In addition, chemical compositions and morphological properties of root repair cements were carried out by energy-dispersive X-ray spectroscopy (EDX).

\subsection{RT-qPCR Gene Expression Analysis}

To evaluate the expression of cementoblastic/osteoblastic-related genes (ALP, CEMP-1, and CAP), $2 \times 10^{4}$ hPDLSCs/well were seeded onto twelve-well plates $(n=3)$ and stimulated with 
undiluted extracts of BCR and TFB, for seven days. Cell cultures without material extracts served as a negative control and cells cultured with an optimized differentiation medium to generate osteoblasts from human mesenchymal stromal cells (StemMACS OsteoDiff Medium; MiltenyiBiotec, Bergisch Gladbach, Germany) served as a positive control. Total RNA was prepared using the RNeasy Mini Kit (Qiagen, Hilden, Germany), and cDNA was synthesized from $1 \mu \mathrm{g}$ of RNA by using iScript ${ }^{\mathrm{TM}}$ Reverse Transcription Supermix for RT-qPCR (Bio-Rad) following the manufacturer's instructions. Changes in gene expression were calculated by the $2-\Delta \Delta C T$ method. The primers used in this study are listed in Table 2.

Table 2. Primers for qPCR analysis.

\begin{tabular}{|c|c|}
\hline GADPH & $\begin{array}{l}\text { Forward } 5^{\prime} \text { TCAGCAATGCCTCCTGCAC } 3^{\prime} \\
\text { Reverse } 5^{\prime} \text { TCTGGGTGGCAGTGATGGC } 3^{\prime}\end{array}$ \\
\hline CEMP1 & $\begin{array}{l}\text { Forward 5' GGGCACATCAAGCACTGACAG 3' } \\
\text { Reverse 5' CCCTTAGGAAGTGGCTGTCCAG 3' }\end{array}$ \\
\hline CAP & $\begin{array}{l}\text { Forward } 5^{\prime} \text { TTTTTCTGGTCGCGTGGACT } 3^{\prime} \\
\text { Reverse } 5^{\prime} \text { TCACCAGCAACTCCAACAGG 3' }\end{array}$ \\
\hline ALP & $\begin{array}{l}\text { Forward } 5^{\prime} \text { TCAGAAGCTCAACACCAACG } 3^{\prime} \\
\text { Reverse } 5^{\prime} \text { TTGTACGTCTTGGAGAGGGC } 3^{\prime}\end{array}$ \\
\hline RUNX2 & $\begin{array}{l}\text { Forward } 5^{\prime} \text { TCCACACCATTAGGGACCATC } 3^{\prime} \\
\text { Reverse } 5^{\prime} \text { TGCTAATGCTTCGTGTTTCCA } 3^{\prime}\end{array}$ \\
\hline
\end{tabular}

\subsection{Alizarin Red Assay}

Mineralization capacity of root repair cements was evaluated using Alizarin red staining. $2 \times 10^{4}$ hPDLSCs /well were seeded onto twelve-well plates $(n=3)$ and proliferated to achieve confluency. Then, cells were stimulated with undiluted extracts of BCR and TFB for 21 days. Cells cultured without extracts served as negative control and cells cultured with OsteoDiff media (MiltenyiBiotec) served as a positive control. At the end of the experimental period, the cells were washed with PBS and fixed for $1 \mathrm{~h}$ using 70\% ethanol. Then, they were incubated with 2\% Alizarin Red solution (Sigma AB, Malmö, Sweden) at room temperature in the dark for $30 \mathrm{~min}$. Finally, the absorbance value at $550 \mathrm{~nm}$ was measured using the microplate reader.

\subsection{Statistical Analysis}

Data were presented as the mean \pm standard deviation (SD). All analyses were carried out using Graph-Pad Prism (version 8.1.0, GraphPad Software, San Diego, CA, USA). Normal data with equal variance was analyzed using one-way analysis of variance (ANOVA) and Tukey's test. Significance was defined when $p \leq 0.05$. All assays were performed at least three times.

\section{Results}

\subsection{Characterization of hPDLSCs Immunophenotype}

FACS analysis showed a mesenchymal phenotype of cells isolated from periodontal tissues. There was a high expression of CD90, CD105, and CD73 (>95\%), and low expression of cell markers CD45, CD34, CD14, and CD20 (<5\%) (Figure 1). 

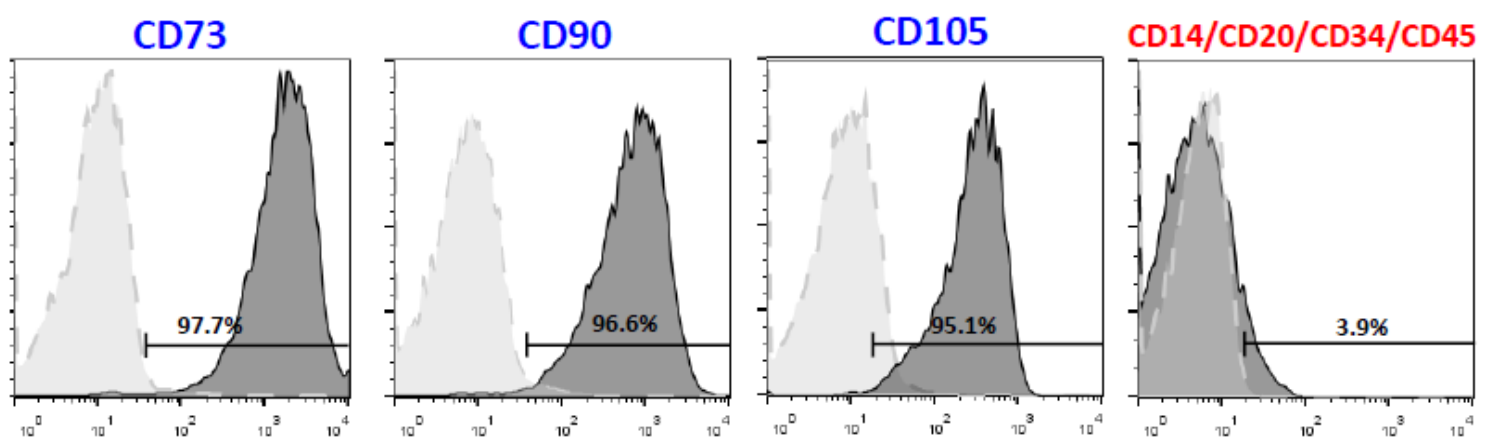

Figure 1. Fluorescence-activated cell sorting (FACS) analysis. Positive expression from cells isolated from periodontal ligament tissue $(<95 \%)$ of mesenchymal stem cells markers CD90, CD105, and CD73 and negative expression for cells markers CD34, CD45, CD14, and CD20 $(<5 \%)$.

\subsection{Cytotoxicity Evaluation}

At $24 \mathrm{~h}$, extracts of Bio-C Repair reduced the viability of hPDLSCs with significant differences as compared with the untreated cells (control) $(p<0.001)$, while TFB exhibited similar cell viability to that of the control. At $48 \mathrm{~h}$, both cements showed adequate cell viability rates, except 1:4 TFB that increased cell viability $(p<0.001)$. Finally, TFB showed slight differences as compared with the control group $(p<0.05)$ after $72 \mathrm{~h}$ of incubation, whereas BCR did not suffer any significant variation of cell viability rates as compared with untreated cells group (Figure 2).
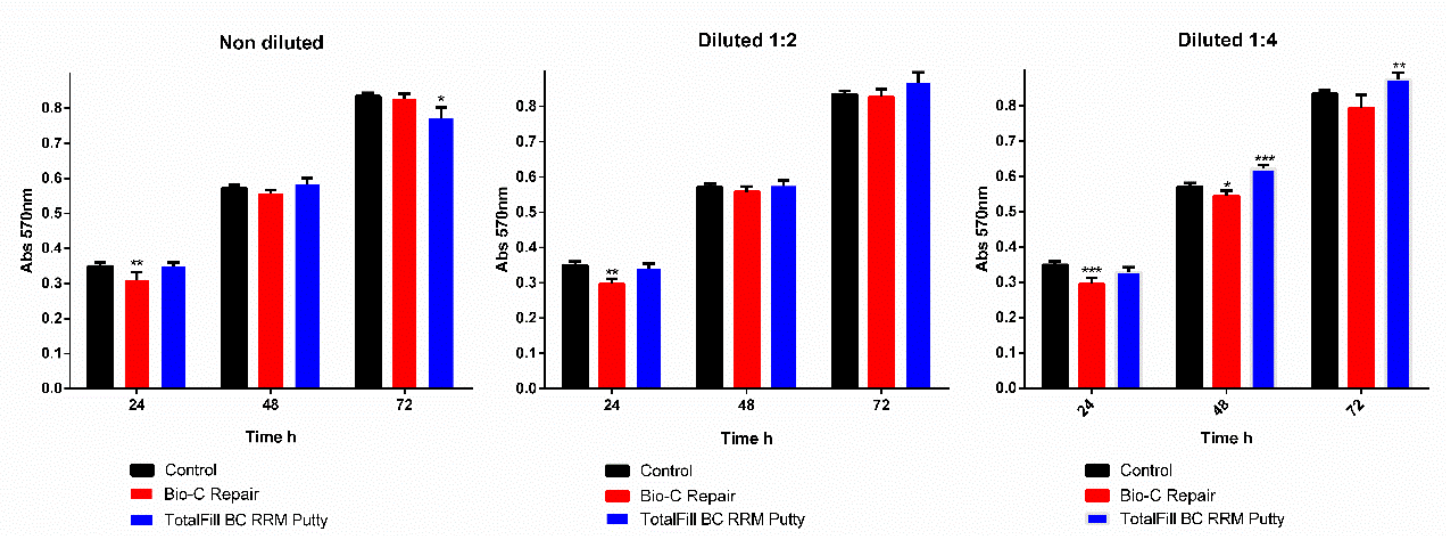

Figure 2. Cytotoxicity assay. Evaluation of human periodontal ligament stem cells (hPDLSCs) treated with Bio-C Repair and TotalFill BC RRM putty eluates. Data shown are the mean $( \pm \mathrm{SD})$ of three different experiments. Cytotoxic differences observed are shown as ${ }^{*} p<0.05,{ }^{* *} p<0.01$, and ${ }^{* * *}$ $p<0.001$, respectively.

\subsection{Scratch Migration Assay}

At all time periods and all dilutions studied, cell migration rates in the TFC group were similar to that of the untreated cells, and no detectable differences were found (Figure 3). In the BCR, at $24 \mathrm{~h}$ in the nondiluted group, significant differences were found $(* * p<0.01)$ and at $48 \mathrm{~h}$ significant differences were found; meanwhile, no statistical difference were revealed at $72 \mathrm{~h}$ in any dilution as compared with the control group wound closure. These results indicate that both cements had similar migration values to those of the control. 


\section{Control Bio-C Repair TotalFill BC RRM Putty}
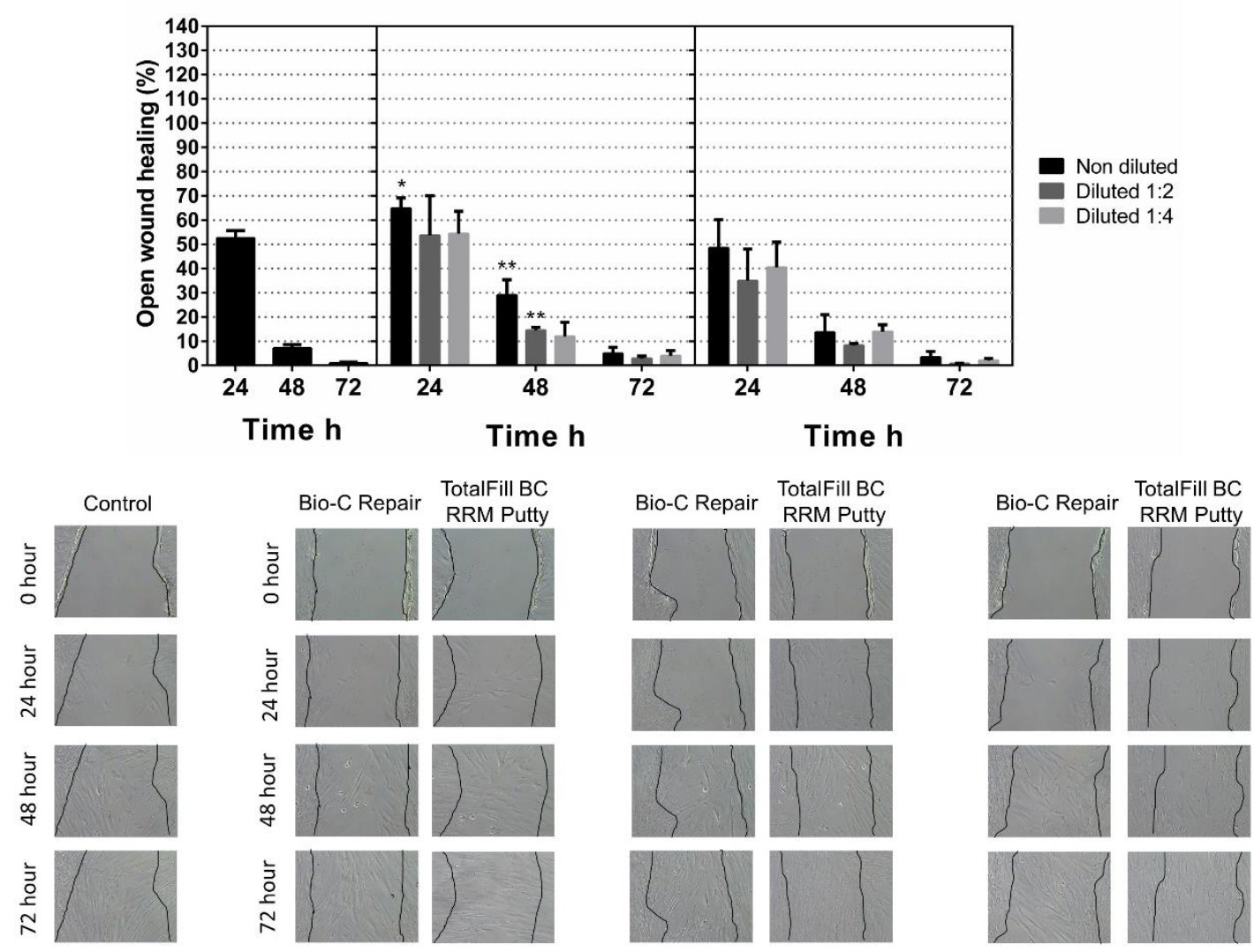

Non diluted

Diluted 1:2

Diluted 1:4

Figure 3. In vitro scratch migration assay. The wound closure was evaluated at $24 \mathrm{~h}, 48 \mathrm{~h}$, and $72 \mathrm{~h}$, in the presence of different material extracts, or without extracts (control group). Data are expressed as fold of the control group (considered as 100\%). Cell migration differences are shown as * $p<0.005$, ** $p<0.01$.

\subsection{Scanning Electronic Microscopy}

Abundant cells were observed in the surface of both cements (Figure 4). The morphology of these cells in contact with these materials suggested an active adhesion interaction with the surface since we can observe multiple prolongations and a flattened morphology. The EDX analysis provided the qualitative semi-quantitative elemental composition of each surface's material, which are represented in Figure 5. BCR and TFB showed the same elemental composition. C, O, and Si showed different $\%$ concentration in both cements. With respect to $\mathrm{Ca}^{2+}, \mathrm{TFB}$ contained a higher $\%$ of $\mathrm{Ca}^{2+}$ and $\mathrm{Zr}$ as compared with BCR. On the other hand, the \% of $\mathrm{Si}$ in BCR was higher as compared with TFB. 


\section{Bio-C Repair}

$100 x$

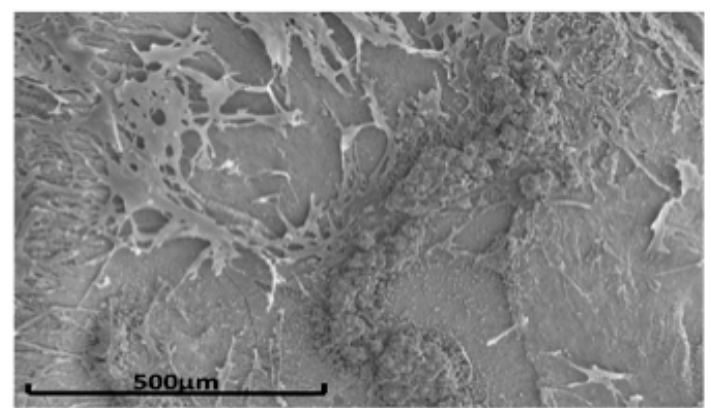

$300 x$

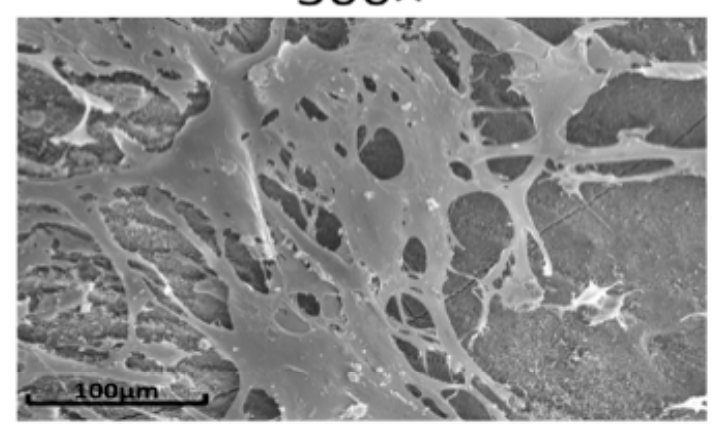

\section{TotalFill BC RRM PUTTY}

$100 \times$

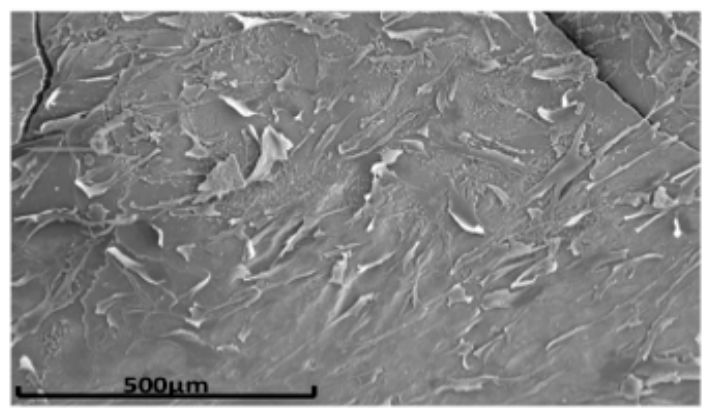

$300 \times$

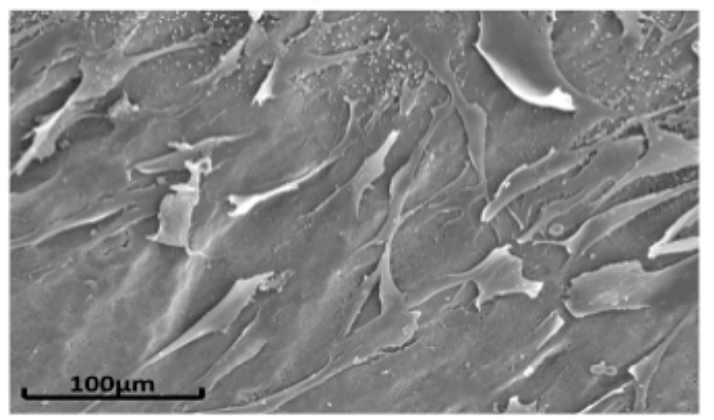

Figure 4. Cell attachment analysis. Adhesion of the stem cells from the periodontal ligament (PDLSCs) on Bio-C Repair (BCR) and TotalFill BC RRM putty (TFB) at $72 \mathrm{~h}$. Scale bar: $100 \mu \mathrm{m}$ and $500 \mu \mathrm{m}$.
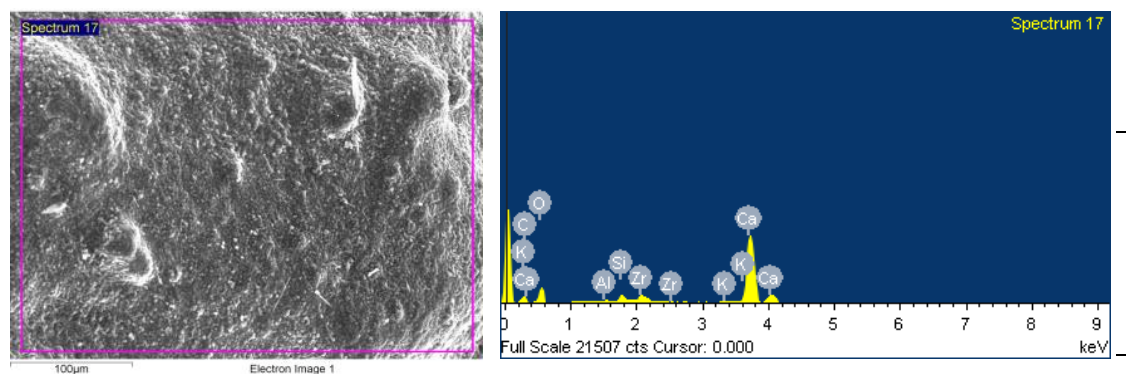

\section{Bio-C Repair}

\begin{tabular}{l|ll}
\hline Element & Weight\% & Atomic\% \\
& & \\
$\mathrm{C} \mathrm{K}$ & 28.93 & 42.60 \\
$\mathrm{OK}$ & 40.13 & 44.37 \\
$\mathrm{Al} \mathrm{K}$ & 0.20 & 0.13 \\
$\mathrm{Si} \mathrm{K}$ & 1.21 & 0.76 \\
$\mathrm{~K} \mathrm{~K}$ & 0.16 & 0.07 \\
$\mathrm{Ca} \mathrm{K}$ & 25.75 & 11.37 \\
$\mathrm{Zr} \mathrm{L}$ & 3.62 & 0.70 \\
& & \\
Totals & 100.00 & \\
\hline
\end{tabular}
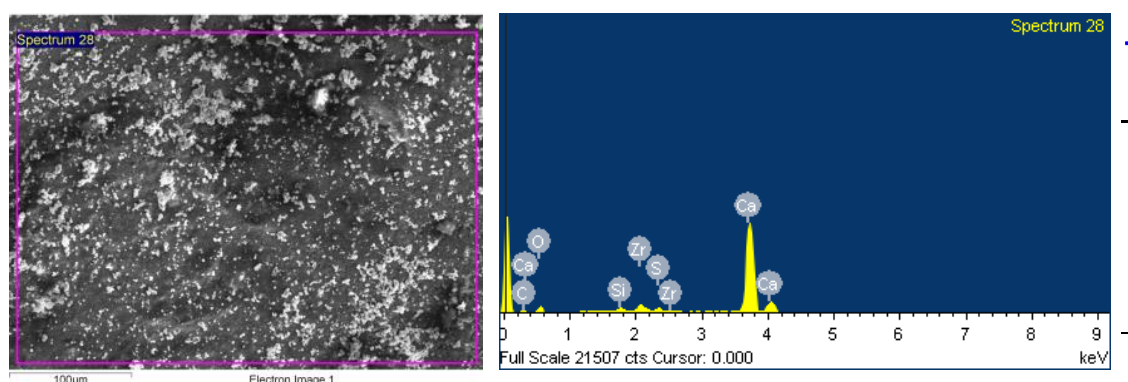

TotalFill BC RRM Putty

\begin{tabular}{l|ll}
\hline Element & Weight\% & Atomic\% \\
C K & 13.72 & 25.66 \\
O K & 32.39 & 45.49 \\
Si K & 0.81 & 0.65 \\
S K & 1.54 & 1.08 \\
Ca K & 45.91 & 25.73 \\
Zr L & 5.63 & 1.39 \\
Totals & 100.00 & \\
\hline \multicolumn{5}{l}{}
\end{tabular}

Figure 5. Scanning electron microscopy with energy-dispersive X-ray analysis (SEM-EDX) evaluation. Surface properties and composition of BCR and TFB. SEM image (left column), EDX spectra (middle column), and table of elements (right column). Scale bar represents $100 \mu \mathrm{m}$ for all images.

\section{5. qPCR Analysis}

At day seven, CAP, CEMP-1, and RUNX2 expression were higher in Osteodiff and BC-Repair groups as compared with TFB and the negative control group $(p<0.001)$ and also the expression of CAP 
and RUNX2 were higher in BCR and TFB as compared with the groups Osteodiff and negative control groups, in different significances (Figure 6) at day 14. GAPDH was used to normalize the results.
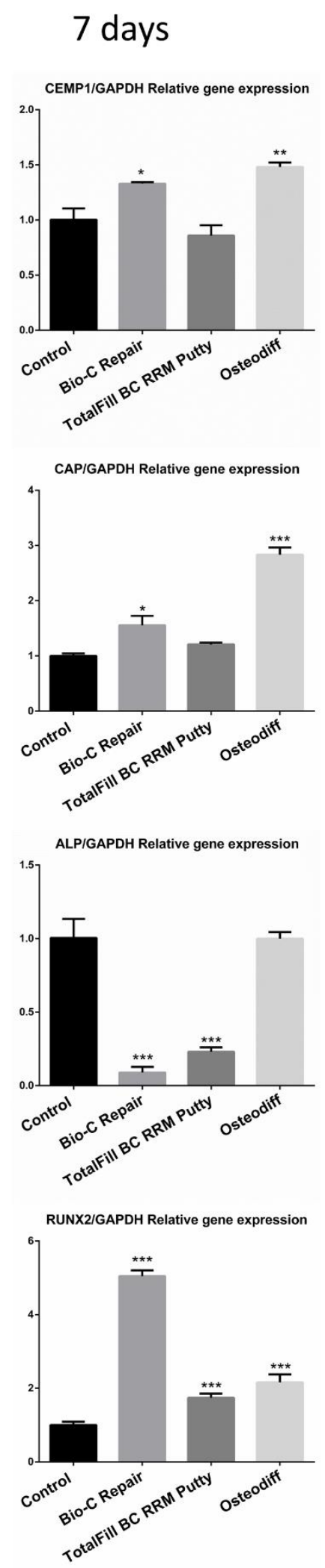

\section{4 days}
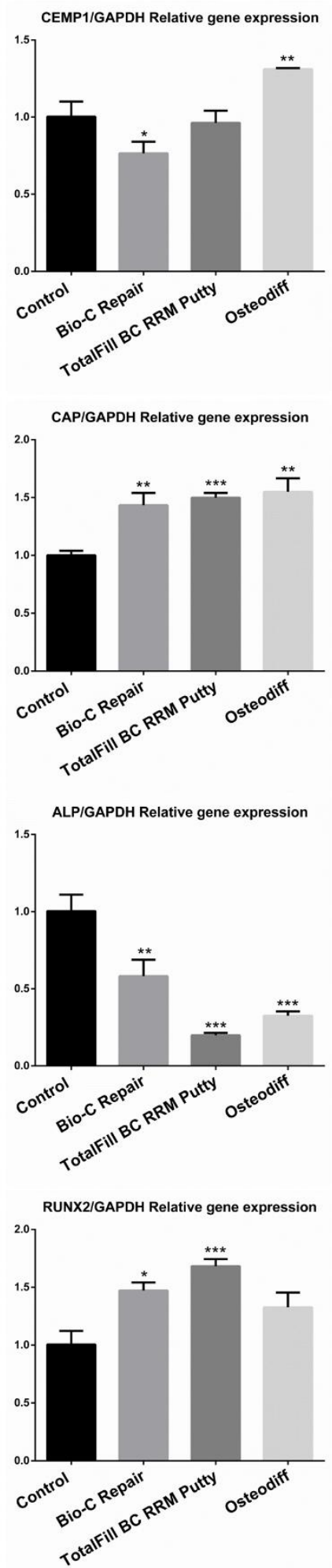

\section{Cementum protein} (CEMP1)

\section{Cementum-derived attachment protein} (CAP)

\section{Alkaline phosphatase \\ (ALP)}

Transcription factor involved in osteoblastic differentiation and skeletal morphogenesis (RUNX2)

Figure 6. qPCR analysis. Gene expression profiles of hPDLSCs treated with undiluted materials showing expression of ALP, CEMP, RUNX2, and CAP genes. Values indicated with a * represent significant differences between the groups. ${ }^{*} p<0.05,{ }^{* *} p<0.01$ and ${ }^{* * *} p<0.001$. 


\subsection{Mineralization Assay}

As shown in Figure 7, TFB and BCR promoted significantly more calcium deposits than the negative control $(p<0.01)$. However, Osteodiff (positive control) exhibited more mineralization capacity than root repair cements $(p<0.001)$.

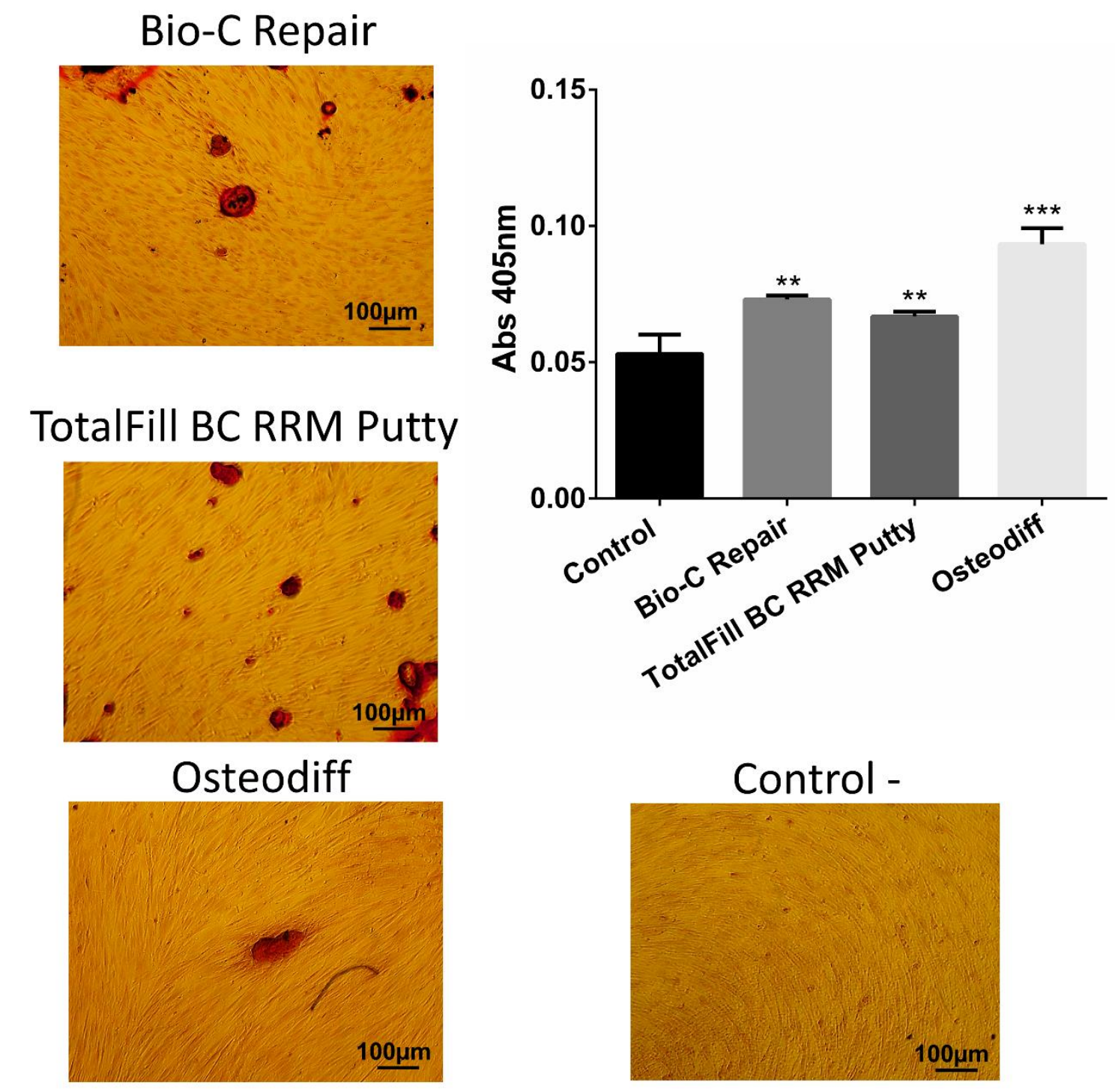

Figure 7. Mineralization capacity of root repair cements. Alizarin Red staining to evaluate the bioactivity potential of BCR and TFB. Differences observed are shown as ${ }^{* *} p<0.01$ and ${ }^{* * *} p<0.001$.

\section{Discussion}

The appearance of different materials to treat dental perforation or to perform apical surgery facilitates our choice of options. It is necessary to know the properties of the materials to determine which one is better for each type of problem [20].

In our study, we compared the cytocompatibility and bioactivity potential of these two new bioactive materials, BCR and TFB, with PDLSCs. We chose this cell type because, in the indications of these materials, PDLSCs have contact with the periodontal ligament which are at the root-end cavity when periapical surgery is done or when iatrogenic perforation is repaired it is next to the periodontal ligament $[10,21]$. Other studies have used dental pulp stem cells with direct pulp capping materials [22], or osteoblast cells when they have also studied endodontic cements [23,24]. Therefore, the clinical situation is crucial for the choice of cell line. 
We used the MTT test due to its ease of performing and its accuracy [25]. In addition, the methylthiazolyldiphenyl-tetrazolium bromide (MTT) assay is commonly accepted for in vitro cytotoxic studies. TFB and BCR showed similar results in terms of cell viability as compared with a control group. In line with this work, previous reports have described similar results, also using the MTT test with TotalFill BC sealer, which has an almost identical composition, except it changes consistency $[25,26]$. Benetti et al. [27] also reported that BCR is a biocompatible material that induces mineralization in vivo. Unsurprisingly, our results evidenced that both cements were safe and did not promote adverse effects on hPDLSCs.

Cellular migration is essential for an apical healing after a retrograde root filling, or after repair of a furcal iatrogenic perforation because it helps in calcified tissue formation [28]. In our study, both materials allow cell migration; this may be due to calcium ions since they favor migration [29]. The SEM-EDX assay showed a high amount of $\mathrm{Ca}^{2+}$ ions in both cements, especially in TFB, which could help increase the $\mathrm{pH}$ of the area and have a positive influence on healing [30]. Our results are consistent with other studies that have shown the migration capacity of the root repair materials. For example, iRoot FS (Innovative Bioceramix, Vancouver, BC, Canada) showed cell migration rates higher than ProRootMTA (Dentsply, Tulsa, OK, USA) [28], or Biodentine (Septodont, St Maur des Fosses, France) has been evidenced by anti-inflammatory properties and favored fibroblast migration to the injury site [31]. Nevertheless, the detailed mechanism of how premixed and putty calcium silicate materials favors cell migration is unknown.

The connection between cells and biomaterial is essential for cell differentiation, and cell attachment has been associated with actin stress fibers [32,33]. Both premixed material's surfaces favored cell adhesion. In our study, hPDLSCs displayed a well interconnected characteristic fibroblastic morphology. This result is congruent with another report that showed that calcium silicate materials facilitated cell attachment and promoted cell proliferation [34]. Furthermore, a biological seal on the root repair materials can be achieved by the interactions between materials and hPDLSCs.

Bioactivity potential is defined as the cellular effects induced by ions or active substances from biomaterials [35]. Our results showed overexpression of CEMP-1, CAP, and Runx2 with BCR on day seven. These genes are involved in the osteo- and cementogenic differentiation of stem cells, and consequently in apical healing. CEMP-1 is related to migration, proliferation, and differentiation of periodontal ligament cells into cementoblast-like cells. CAP promotes maturation and deposition of the mineralized extracellular matrix. Runx2 is considered a transcriptional regulation factor, closely associated with the early stage of osteogenesis [36,37]. Previous data have shown the overexpression of these genes in the presence of bioactive endodontic materials [38]. In agreement with our results, Lee et al. [39] showed overexpression of osteogenic markers in the presence of other bioactive cements such as ProRootMTA (Dentsply, Tulsa, USA), Biodentine, and Bioaggregate (Innovative Bioceramix, Vancouver, BC, Canada). Our group also demonstrated that GuttaFlow Bioseal (Coltène/Whaledent AG, Altstatten, Switzerland), a bioactive silicon material, induced AMELX, AMBN, CAP, and CEMP1 overexpression, and reduced ALP expression in hPDLSCs [40].

Alizarin Red assay was assessed to evaluate mineralization capacity of the root repair cements; both cements produced more calcium deposits than the negative control, confirming the inductive effect of both root repair materials on the mineralization and differentiation of hPDLSCs. Previous reports have shown that putty calcium silicate materials induced mineralization $[25,27]$. Calcium silicates are the main components of both cements (Table 1) which justifies the result obtained.

The number of studies on these new calcium silicate-based materials is meager, and it would be interesting to develop studies on mechanical, sealing, and cytotoxicity properties.

\section{Conclusions}

These results suggest that BCR and TFB are biologically appropriate materials to be used as root repair material or root-end filling. 
Author Contributions: Investigation and methodology, S.L.-G. and D.G.-B.; supervision and visualization; conceptualization and data curation, M.R.P.-L., M.P.P.-L. and J.G.-G.; investigation, methodology and writing-original draft, A.L., C.L.; conceptualization, formal analysis, project administration, supervision, validation and writing-review \& editing, L.F. and G.S.; investigation, methodology, project administration, resources, writing-original draft and writing-review \& editing, F.J.R.-L. All authors have read and agreed to the published version of the manuscript.

Funding: The Spanish Net of Cell Therapy (TerCel), RETICS subprograms of the I+D+I 2013-2016 Spanish National Plan, and project "RD16/0011/0001" funded by the Instituto de Salud Carlos III to JMM and co-funded by the European Regional Development Fund supported this work.

Conflicts of Interest: The authors declare that there is no conflict of interest related to this article.

\section{References}

1. Estrela, C.; Decurcio, D.A.; Rossi-Fedele, G.; Silva, J.A.; Guedes, O.A.; Borges, A.H. Root perforations: A review of diagnosis, prognosis and materials. Braz. Oral Res. 2018, 32, e73. [CrossRef] [PubMed]

2. Abusrewil, S.M.; McLean, W.; Scott, J.A. The use of bioceramics as root-end filling materials in periradicular surgery: A literature review. Saudi Dent. J. 2018, 30, 273-282. [CrossRef] [PubMed]

3. Khayat, A. Histological observations of periradicular healing following root canal treatment. Aust. Endod. J. 2005, 31, 101-105. [CrossRef] [PubMed]

4. Tang, J.J.; Shen, Z.S.; Qin, W.; Lin, Z. A comparison of the sealing abilities between biodentine and mta as root-end filling materials and their effects on bone healing in dogs after periradicular surgery. J. Appl. Oral Sci. 2019, 27, e20180693. [CrossRef] [PubMed]

5. von Arx, T.; Jensen, S.S.; Janner, S.F.M.; Hanni, S.; Bornstein, M.M. A 10-year Follow-up Study of 119 Teeth Treated With Apical Surgery and Root-end Filling with Mineral Trioxide Aggregate. J. Endod. 2019, 45, 394-401. [CrossRef]

6. Rodríguez-Lozano, F.J.; Bueno, C.; Insausti, C.L.; Meseguer, L.; Ramírez, M.C.; Blanquer, M.; Marin, N.; Martínez, S.; Moraleda, J.M. Mesenchymal stem cells derived from dental tissues. Int. Endod. J. 2011, 44, 800-806. [CrossRef]

7. Spagnuolo, G.; Codispoti, B.; Marrelli, M.; Rengo, C.; Rengo, S.; Tatullo, M. Commitment of Oral-Derived Stem Cells in Dental and Maxillofacial Applications. Dent. J. 2018, 6, 72. [CrossRef]

8. Vidovic Zdrilic, I.; de Azevedo Queiroz, I.O.; Matthews, B.G.; Gomes-Filho, J.E.; Mina, M.; Kalajzic, I. Mineral trioxide aggregate improves healing response of periodontal tissue to injury in mice. J. Periodontal Res. 2017, 52, 1058-1067. [CrossRef]

9. Leprince, J.G.; Zeitlin, B.D.; Tolar, M.; Peters, O.A. Interactions between immune system and mesenchymal stem cells in dental pulp and periapical tissues. Int. Endod. J. 2012, 45, 689-701. [CrossRef]

10. Yoshino, P.; Nishiyama, C.K.; Modena, K.C.; Santos, C.F.; Sipert, C.R. In vitro cytotoxicity of white MTA, MTA Fillapex ${ }^{\circledR}$ and Portland cement on human periodontal ligament fibroblasts. Braz. Dent. J. 2013, 24, 111-116. [CrossRef]

11. Gandolfi, M.G.; Spagnuolo, G.; Siboni, F.; Procino, A.; Rivieccio, V.; Pelliccioni, G.A.; Prati, C.; Rengo, S. Calcium silicate/calcium phosphate biphasic cements for vital pulp therapy: Chemical-physical properties and human pulp cells response. Clin. Oral Investig. 2015, 19, 2075-2089. [CrossRef] [PubMed]

12. De-Deus, G.; Canabarro, A.; Alves, G.; Linhares, A.; Senne, M.I.; Granjeiro, J.M. Optimal cytocompatibility of a bioceramic nanoparticulate cement in primary human mesenchymal cells. J. Endod. 2009, 35, 1387-1390. [CrossRef] [PubMed]

13. Torabinejad, M.; Parirokh, M.; Dummer, P.M.H. Mineral trioxide aggregate and other bioactive endodontic cements: An updated overview-Part II: Other clinical applications and complications. Int. Endod. J. 2018, 51, 284-317. [CrossRef] [PubMed]

14. Parirokh, M.; Torabinejad, M. Mineral trioxide aggregate: A comprehensive literature review-Part III: Clinical applications, drawbacks, and mechanism of action. J. Endod. 2010, 36, 400-413. [CrossRef] [PubMed]

15. Torabinejad, M.; Parirokh, M. Mineral trioxide aggregate: A comprehensive literature review-Part II: Leakage and biocompatibility investigations. J. Endod. 2010, 36, 190-202. [CrossRef] [PubMed]

16. Parirokh, M.; Torabinejad, M. Mineral trioxide aggregate: A comprehensive literature review-Part I: Chemical, physical, and antibacterial properties. J. Endod. 2010, 36, 16-27. [CrossRef] 
17. Da Silva, E.J.; Zaia, A.A.; Peters, O.A. Cytocompatibility of calcium silicate-based sealers in a three-dimensional cell culture model. Clin. Oral Investig. 2017, 21, 1531-1536. [CrossRef]

18. International Organization for Standardization. Biological Evaluation of Medical Devices_Part 5: Tests for In Vitro Cytotoxicity, ISO 10993-5; ISO: Geneva, Switzerland, 2009.

19. Tomas-Catala, C.J.; Collado-Gonzalez, M.; Garcia-Bernal, D.; Onate-Sanchez, R.E.; Forner, L.; Llena, C.; Lozano, A.; Moraleda, J.M.; Rodríguez-Lozano, F.J. Biocompatibility of New Pulp-capping Materials NeoMTA plus, MTA Repair HP, and Biodentine on Human Dental Pulp Stem Cells. J. Endod. 2018, 44, 126-132. [CrossRef]

20. Prati, C.; Gandolfi, M.G. Calcium silicate bioactive cements: Biological perspectives and clinical applications. Dent. Mater. 2015, 31, 351-370. [CrossRef]

21. Michel, A.; Erber, R.; Frese, C.; Gehrig, H.; Saure, D.; Mente, J. In vitro evaluation of different dental materials used for the treatment of extensive cervical root defects using human periodontal cells. Clin. Oral Investig. 2017, 21, 753-761. [CrossRef]

22. Wu, T.; Xu, C.; Du, R.; Wen, Y.; Chang, J.; Huan, Z.; Zhu, Y. Effects of silicate-based composite material on the proliferation and mineralization behaviors of human dental pulp cells: An in vitro assessment. Dent. Mater. J. 2018, 37, 889-896. [CrossRef] [PubMed]

23. Gomes-Cornelio, A.L.; Rodrigues, E.M.; Salles, L.P.; Mestieri, L.B.; Faria, G.; Guerreiro-Tanomaru, J.M.; Tanomaru-Filho, M. Bioactivity of MTA Plus, Biodentine and an experimental calcium silicate-based cement on human osteoblast-like cells. Int. Endod. J. 2017, 50, 39-47. [CrossRef] [PubMed]

24. Lee, B.N.; Hong, J.U.; Kim, S.M.; Jang, J.H.; Chang, H.S.; Hwang, Y.C.; Hwang, I.N.; Oh, W.M. Anti-inflammatory and Osteogenic Effects of Calcium Silicate-based Root Canal Sealers. J. Endod. 2019, 45, 73-78. [CrossRef] [PubMed]

25. Zordan-Bronzel, C.L.; Tanomaru-Filho, M.; Rodrigues, E.M.; Chavez-Andrade, G.M.; Faria, G.; Guerreiro-Tanomaru, J.M. Cytocompatibility, bioactive potential and antimicrobial activity of an experimental calcium silicate-based endodontic sealer. Int. Endod. J. 2019, 52, 979-986. [CrossRef] [PubMed]

26. Colombo, M.; Poggio, C.; Dagna, A.; Meravini, M.V.; Riva, P.; Trovati, F.; Pietrocola, G. Biological and physico-chemical properties of new root canal sealers. J. Clin. Exp. Dent. 2018, 10, e120-e126. [CrossRef] [PubMed]

27. Benetti, F.; Queiroz, I.O.A.; Cosme-Silva, L.; Conti, L.C.; Oliveira, S.H.P.; Cintra, L.T.A. Cytotoxicity, Biocompatibility and Biomineralization of a New Ready-for-use Bioceramic Repair Material. Braz. Dent. J. 2019, 30, 325-332. [CrossRef]

28. Liu, Y.; Liu, X.M.; Bi, J.; Yu, S.; Yang, N.; Song, B.; Chen, X. Cell migration and osteo/odontogenesis stimulation of iRoot FS as a potential apical barrier material in apexification. Int. Endod. J. 2019. [CrossRef]

29. Chen, L.; Zheng, L.; Jiang, J.; Gui, J.; Zhang, L.; Huang, Y.; Chen, X.; Ji, J.; Fan, Y. Calcium Hydroxide-induced Proliferation, Migration, Osteogenic Differentiation, and Mineralization via the Mitogen-activated Protein Kinase Pathway in Human Dental Pulp Stem Cells. J. Endod. 2016, 42, 1355-1361. [CrossRef]

30. Quintana, R.M.; Jardine, A.P.; Grechi, T.R.; Grazziotin-Soares, R.; Ardenghi, D.M.; Scarparo, R.K.; Grecca, F.S.; Kopper, P.M.P. Bone tissue reaction, setting time, solubility, and $\mathrm{pH}$ of root repair materials. Clin. Oral Investig. 2019, 23, 1359-1366. [CrossRef]

31. Giraud, T.; Jeanneau, C.; Bergmann, M.; Laurent, P.; About, I. Tricalcium Silicate Capping Materials Modulate Pulp Healing and Inflammatory Activity In Vitro. J. Endod. 2018, 44, 1686-1691. [CrossRef]

32. Lv, F.; Zhu, L.; Zhang, J.; Yu, J.; Cheng, X.; Peng, B. Evaluation of the in vitro biocompatibility of a new fast-setting ready-to-use root filling and repair material. Int. Endod. J. 2017, 50, 540-548. [CrossRef]

33. Lo Giudice, R.; Puleio, F.; Rizzo, D.; Alibrandi, A.; Lo Giudice, G.; Centofanti, A.; Fiorillo, L.; Di Mauro, D.; Nicita, F. Comparative Investigation of Cutting Devices on Bone Blocks: An SEM Morphological Analysis. Appl. Sci. 2019, 9, 351. [CrossRef]

34. Luo, T.; Liu, J.; Sun, Y.; Shen, Y.; Zou, L. Cytocompatibility of biodentine and iRoot FS with human periodontal ligament cells: An in vitro study. Int. Endod. J. 2018, 51, 779-788. [CrossRef] [PubMed]

35. Vallittu, P.K.; Boccaccini, A.R.; Hupa, L.; Watts, D.C. Bioactive dental materials-Do they exist and what does bioactivity mean? Dent. Mater. 2018, 34, 693-694. [CrossRef] [PubMed]

36. Wang, Y.; Zhou, Y.; Jin, L.; Pang, X.; Lu, Y.; Wang, Z.; Yu, Y.; Yu, J. Mineral trioxide aggregate enhances the osteogenic capacity of periodontal ligament stem cells via NF-kb and MAPK signaling pathways. J. Cell Physiol. 2018, 233, 2386-2397. [CrossRef] 
37. Lopez-Garcia, S.; Myong-Hyun, B.; Lozano, A.; Garcia-Bernal, D.; Forner, L.; Llena, C.; Guerrero-Girones, J.; Murcia, L.; Rodriguez-Lozano, F.J. Cytocompatibility, bioactivity potential, and ion release of three premixed calcium silicate-based sealers. Clin. Oral Investig. 2019. [CrossRef]

38. Tatullo, M.; Spagnuolo, G.; Codispoti, B.; Zamparini, F.; Zhang, A.; Esposti, M.D.; Aparicio, C.; Rengo, C.; Nuzzolese, M.; Manzoli, L.; et al. Pla-Based Mineral-Doped Scaffolds Seeded with Human Periapical Cyst-Derived MSCs: A Promising Tool for Regenerative Healing in Dentistry. Materials 2019, 12, 597. [CrossRef]

39. Lee, B.N.; Lee, K.N.; Koh, J.T.; Min, K.S.; Chang, H.S.; Hwang, I.N.; Hwang, Y.C.; Oh, W.M. Effects of 3 endodontic bioactive cements on osteogenic differentiation in mesenchymal stem cells. J. Endod. 2014, 40, 1217-1222. [CrossRef]

40. Rodriguez-Lozano, F.J.; Collado-Gonzalez, M.; Tomas-Catala, C.J.; Garcia-Bernal, D.; Lopez, S.; Onate-Sanchez, R.E.; Moraleda, J.M.; Murcia, L. GuttaFlow Bioseal promotes spontaneous differentiation of human periodontal ligament stem cells into cementoblast-like cells. Dent. Mater. 2019, 35, 114-124. [CrossRef]

(C) 2020 by the authors. Licensee MDPI, Basel, Switzerland. This article is an open access article distributed under the terms and conditions of the Creative Commons Attribution (CC BY) license (http://creativecommons.org/licenses/by/4.0/). 